\title{
A Review on Taxol producing endophytes isolated from medicinal plants and their potential applications
}

\author{
${ }^{*}$ Ch Saahithi ${ }^{1}$, Mallikharjuna Raj Kampally ${ }^{2}$, Raja Rao P4, Swapna V ${ }^{4}$ \\ ${ }^{1}$ Research Scholar \\ 2Research Scholar \\ ${ }^{3}$ Professor \\ ${ }^{4}$ Asst Professor \\ 1,2,3\&4 University College of Technology, Osmania University, Tarnaka, \\ Hyderabad. Pin: 500007 \\ 1Saahithi1990@gmail.com, ${ }^{2}$ malleshrebs@gmail.com, ${ }^{3}$ proddoku_rr@yahoo.com, \\ ${ }^{4}$ swapnavad2003@googlemail.com
}

\begin{abstract}
Taxol, commercially available as palcitaxel is a potent anticancer drug which has been naturally produced by pacific yew tree. This molecule has been included in the WHO's list of essential medicines. This paper summarises the different sources of Taxol production, starting from initial isolations from Pacific yew tree which was followed by hairy root cultures and during the last decade, much focus was on endophytes as potential sources for Taxol production. Further, this review specifically talks about the medicinal plant Terminalia arjuna and its medicinal values with regard to its endophytes and their capability of producing Taxol. The process of initial screening, purification and media optimization for increasing the yields of secondary metabolites is also discussed.
\end{abstract}

Keywords: Taxol, Terminalia arjuna, Endophytes, Media optimization

\section{Introduction}

Bioactive compounds has been a subject of study since decades. Many of the current pharmaceutical drugs are synthesised and developed based on natural products. Before the advancements in the fermentation and chemical engineering techniques, plants were used as medicines by ancient herbal practitioners. India has been a habitat for thousands of herbal plants and books like Sushrutha Samhitha give us detailed description about the medical applications of many of the traditionally used herbal plants. The major challenge faced by plant based therapies is the yields of the drug that are obtained from these plants. For extraction of 1 gram of bioactive molecule, hundreds of plants are to subjected to extracation processes. In order to overcome these hurdles, scientists have started looking for alternative sources for these bioactive molecules. With the technological advancements in the pharmaceutical industry most of the high potential natural products like alkaloids, terpenoids, flavanoids are currently being produced in a 
synthetic way. The major drawback for these synthetic drugs are the side effects that they cause in patients. Most of the current available chemotherapy and radiotherapy medications result is side effects like hair loss, normal cell death along with cancer cells, decreased count of immune cells.Vinca alkaloids, Taxol, Podophyllotoxins are a few compounds to mention which have currently being produced synthetically and have huge potential in curing life threatening diseases like cancer. Taxol has been an US-FDA approved drug for treating breast cancer ${ }^{[1,2]}$.

In the past few decades, scientists have started working on finding alternative sources for the production of these bioactive compounds apart from plants and synthetic methods. In that process, endophytes have been identified. Endophytes are the microorganisms that live in symbiotic relationship with plants. They are known to produce bioactive compounds similar to their host plants. These endophytes are known to provide protection to their host plants against various biotic and abiotic stress factors. Due to this symbiotic association, these endophytes have similar metabolic pathways being expressed in them as that of host plant. The major advantage for choosing endophytes as a source of bioactive compounds is that they can be grown in a cost effective way in large quantities. The current review focuses on the different endophytic fungi isolated from various medicinal plants and the potential applications of these fungus extracts in curing different chronic disorders.

Endophytes are the bacterial or fungal organisms which live in symbiotic association with the host plant (either on the surface or reside inside) and produce similar secondary metabolites to that of the host plant ${ }^{[1,2,3,4]}$. They apparently do not cause any damage to the host plant. In recent years as mentioned earlier people have been working to produce high value compounds from these endophytes using novel biotechnological approaches and strain engineering techniques. In this regard let us discuss the recent studies and future prospects for endophytes isolated from medicinal plants.

\section{Taxol}

It is a chemotherapeutic agent that has been developed for cancer treatment in the past decade. It is a diterpenoid with an unusual oxytane ring and a tricyclic core. It was first naturally derived from Pacific yew tree (Taxus brevifolia) in Alaska, North California.

Taxol molecule is a inhibitor of mitotic spindle disassembly. It prevents the separation of mitotic spindle fibres, because of which chromosomes are unable to attain the metaphase structure. Thus this results in arrest of cell cycle or reversion of cell cycle to G0 phase which triggers apoptosis and cell death.

It has already been shown to be very effective against ovarian and breast cancer, and recent clinical trials have shown that Taxol may also be useful agents in the 
treatment of non-small-cell lung cancer, head and neck cancer and various other forms of the disease. Several techniques like callus culture, hairy root culture, shoot cultures, metabolic engineering have been used to increase the yield of this high value compounds. Despite these continuous efforts desired levels of production of these metabolites has not been achieved.

\subsection{Taxol producing endophytes}

Taxol is produced naturally from Taxus plant. It was first isolated from bark of Taxus brevifolia. There has been reports of many Endophytes isolated from these Taxus plants which produce Taxol molecule. To mention a few endophytes which haven isolated from Taxus species include- Taxomyces andreanae, Ozonium sp, Cladosporium, Aspergillus aculeatinus, Paraconiothyrium, Aspergillus fumigatus and Alternaria tenuissima, Penicillium aurantiogriseum, Stemphylium sedicola, Gliocladium, Fusarium redolens, Gibberella intermedia, Mucor rouxianus, Fusarium solani, Cladosporium cladosporoides MD2, Aspergillus candidus MD3, Fusarium redolens, Taxomyces andreanae,, Colletotrichum gloeosporioides, Guignardia mangiferae ${ }^{[87,88,89,90,91]}$. An endophyte called pestalotiopsis versicolor isolated from fresh leaves and bark of Taxus cuspidate produced 478microgram/lit Taxol. The below table gives the list of Taxol producing endophytes isolated from different medicinal plants.

Table 1: List of Taxol producing Endophytes ${ }^{[37]}$

\begin{tabular}{|c|c|c|c|}
\hline SI.No & Endophyte & Host plant & $\begin{array}{l}\text { Qunatity in } \\
\text { microgram/lit }\end{array}$ \\
\hline 1 & Taxomyces andreanae & Taxus brevifolia & $0.024-0.05$ \\
\hline 2 & Pestalotiopsis microspora & Taxus walachiana & $60-70$ \\
\hline 3 & Pestalotiopsis microspora & $\begin{array}{l}\text { Taxodium } \\
\text { distichurn }\end{array}$ & $0.014-1.487$ \\
\hline & Pestalotiopsis sp. & Wollemia nobilis & $0.127-0.485$ \\
\hline 5. & Periconia sp & $\begin{array}{l}\text { Torreya } \\
\text { grandifolia }\end{array}$ & $0.030-0.831$ \\
\hline 6 & Tubercularia sp. & Taxus mairei- & \\
\hline 7 & Nodulisporium sylviforme & Taxus cuspidata & $51.06-125.7$ \\
\hline 8 & Papulaspora sp. & $\begin{array}{l}\text { Taxus chinensis } \\
\text { var. Mairei }\end{array}$ & 10.25 \\
\hline 9 & Botrytis sp. & $\begin{array}{l}\text { Taxus chinensis } \\
\text { var. mairei }\end{array}$ & 161.24 \\
\hline 10 & Fusarium maire & Taxus mairei & 225.2 \\
\hline 11 & Ozonium sp. & $\begin{array}{l}\text { Taxus chinensis } \\
\text { var. mairei }\end{array}$ & $4-18$ \\
\hline 12 & Botryodiplodia & Taxus baccata & 280.5 \\
\hline
\end{tabular}




\begin{tabular}{|c|c|c|c|}
\hline & theobromae & & \\
\hline 13 & Pestalotiopsis pauciseta & $\begin{array}{l}\text { Cardiospermum } \\
\text { helicacabum }\end{array}$ & 113.3 \\
\hline 14 & $\begin{array}{l}\text { Colletotrichum } \\
\text { gleospoiroides }\end{array}$ & $\begin{array}{l}\text { Justicia } \\
\text { gendarussa }\end{array}$ & 163.4 \\
\hline 15 & $\begin{array}{l}\text { Bartalinia robillardoides } \\
\text { Tassi }\end{array}$ & $\begin{array}{l}\text { Aegle marmelos } \\
\text { Correa ex Roxb }\end{array}$ & 187.6 \\
\hline 16 & Phyllosticta citricarpa & Citrus medica & $137-265$ \\
\hline 17 & Phyllosticta spinarum & Cupressus sp. & $125-235$ \\
\hline 18 & $\begin{array}{l}\text { Phyllosticta melochiae } \\
\text { Yates }\end{array}$ & $\begin{array}{l}\text { Melochia } \\
\text { Corchorifolia L }\end{array}$ & 274 \\
\hline 19 & Fusarium solani & Taxus celebica & 1.6 \\
\hline 20 & $\begin{array}{l}\text { Fusarium } \\
\text { arthrosporioides }\end{array}$ & Taxus cuspidata & 131 \\
\hline 21 & Fusarium solani & Taxus chinensis & 163.35 \\
\hline 22 & Aspergillus fumigatus & Podocarpus sp. & 560 \\
\hline 23 & $\begin{array}{l}\text { Aspergillus niger var. } \\
\text { Taxi }\end{array}$ & Taxus cuspidata & 273.46 \\
\hline 24 & Phomopsis sp. BKH 27 & Taxus cuspidata & 418 \\
\hline 25 & Phomopsis sp. BKH 30 & Gingko biloba & 372 \\
\hline 26 & Phomopsis sp. BKH 35 & Larix leptolepis & 334 \\
\hline 27 & Phyllosticta dioscoreae & $\begin{array}{l}\text { Hibiscus rosa- } \\
\text { sinensis }\end{array}$ & 298 \\
\hline 28 & Chaetomella raphigera & Terminalia arjuna & 79.6 \\
\hline 29 & Pestalotiopsis terminaliae & Terminalia arjuna & 211.1 \\
\hline 30 & $\begin{array}{l}\text { Cladosporium } \\
\text { cladosporioides MD2 }\end{array}$ & Taxus media & 800 \\
\hline 31 & Metarhizium anisopliae & Taxus chinensis & 846.1 \\
\hline 32 & $\begin{array}{l}\text { Colletotrichum } \\
\text { gloeosporioides }\end{array}$ & Plumeria acutifolia & 57.54 \\
\hline 33 & $\begin{array}{l}\text { Paraconiothyrium } \\
\text { sp. }\end{array}$ & Taxus media & 40 \\
\hline 34 & Lasiodiplodia theobromae & Morinda citrifolia & 245 \\
\hline 35 & Fusarium oxysporum & $\begin{array}{l}\text { Rhizophora } \\
\text { annamalayana }\end{array}$ & 172.3 \\
\hline 36 & Phoma betae & Ginkgo biloba & 795 \\
\hline 37 & Fusarium solani & Tylophora indica & 157 \\
\hline 38 & Chaetomium sp. & Michelia & 77.23 \\
\hline
\end{tabular}




\begin{tabular}{|c|c|c|c|}
\hline & & champaca $L$ & \\
\hline 39 & Fusarium redolens & $\begin{array}{l}\text { Taxus baccata } L \text {. } \\
\text { subsp. wallichiana }\end{array}$ & 66 \\
\hline 40 & $\begin{array}{l}\text { Penicillium } \\
\text { aurantiogriseum NRRL } \\
62431\end{array}$ & Corylus avellana & $70-350$ \\
\hline 41 & Cladosporium oxysporum & Moringa oleifera & 550 \\
\hline 42 & Phoma sp & $\begin{array}{l}\text { Calotropis } \\
\text { gigantea }\end{array}$ & 152.26 \\
\hline 43 & $\begin{array}{l}\text { Paraconiothyrium } \\
\text { variabile }\end{array}$ & Taxus baccata & 14.7 \\
\hline 44 & Phoma medicaginis & $\begin{array}{l}\text { Taxus wallichiana } \\
\text { var. Mairei }\end{array}$ & 1215 \\
\hline 45 & $\begin{array}{l}\text { Aspergillus aculeatinus } \\
\text { Tax-6 }\end{array}$ & $\begin{array}{l}\text { Taxus chinensis } \\
\text { var. Mairei }\end{array}$ & $334.92-1337.56$ \\
\hline 46 & Cladosporium $s p$ & Taxus baccata & $\begin{array}{l}152.5 \mathrm{mg} / \mathrm{Kg} \text { dry } \\
\text { weight }\end{array}$ \\
\hline 47 & Alternaria brassicicola & Terminalia arjuna & $140.8 \mu \mathrm{gm} / \mathrm{lit}$ \\
\hline
\end{tabular}

\section{Terminalia arjuna}

Terminalia arjuna is a deciduous tree which grows up to a height of $30 \mathrm{~m}$. It belongs to Combretaceae family. It occurs naturally across the banks of streams and rivers. This species is a characteristic part of dry tropical riverine forests.

T. arjuna has been widely used in Ayurvedic medicine for the treatment of cancer, dermatological and gynaecological complaints, heart diseases and urinary disorders. The bark is acrid, an astringent and tonic, and is useful in treatment of high blood pressure and ulcersThe cancer cell growth inhibitory constituent (luteolin) has been isolated from bark, stem and leaves of T. arjuna. Luteolin has also been shown to have specific anti-bacterial activity against Neisseria gonorrhoea. It can also be used as alexiteric, styptic, tonic and anthelmintic and it is useful in fractures, inflammation and wounds and ulcers.

Many people have studied the chemical constituents produced by the plant naturally which shows the richness of different bioactive secondary metabolites present in Terminala arjuna and stands as a proof of concept for its medicinal properties. This data would also help us to expect what kind of compounds can be produced by the endophytes that reside on this plant parts. 


\section{Endophytes isolated from Terminalia arjuna}

But to our surprise, it was identified that certain endophytes growing on non Taxol producing plants also express the Taxol synthesis genes and they produce Taxol. One such plant is Terminalia arjuna. Recent studies has shown a wide range of endophytes isolated from Terminalia arjuna which produced different kinds of secondary metabolites. Among them Taxol is one such molecule. To name a endophyte isolated from Terminalia and that have been showing the Taxol production is Pestalotiopsis ${ }^{[5]}$. Hence further studies in this direction would help in identifying more Taxol producing endophytes from Terminalia arjuna. Terminalia has been a host for wide range of endophytes like Alternaria, Aspergillus, Diaporthe. These have shown anti-inflammatory and antioxidant activites. Pencillium thiomii, Alternaria and Candida sps were isolated from barks of Terminalia chebula which showed anti-inflammatory, antioxidant and anticancer activities ${ }^{[6,7,8,9]}$.

A few endophytes isolated from different terminalia species were found to be rich in flavanoids, phenols, terpenoids and have even demonstrated decrease in cholesterol levels under invitro and invivo studies in albino rats. Certain endophytes isolated from roots of Terminalia arjuna have been effective and showed cytotoxicity against MCF-7 and NF-8 cell lines. The endophyte Aspergillus fumigates isolated from Terminalia arjuna produced Taxol upto 84.41microgram/lit. Apart from Taxus and Terminalia genera, endophytes isolated from different plants like Hazel plant, Salacia and mangroves like Rhizophora annamalayana also showed Taxol production.

Fungal endophytes have been studied for their medicinal values. Few endophytes have been isolated from bark of Terminalia arjuna and their antibacterial activity was tested against pathogenic microorganisms Bacillus subtilis, Staphylococusaures, E.Coli , Klebsiella pneumonia and anticancer activity was tested against MCF-\& cell lines. ${ }^{[10]}$

\section{Isolation of endophytic fungi}

Proper screening and isolation of endophytes from different plant material is a very important and crucial step. The rest of the process depends upon the endophytic strains that are isolated ${ }^{[11,12,13,14]}$

As most of the authors described, endophytes are isolated in a two step process. Initially the selected plant material is to be properly surface sterilized and inoculated onto water agar plates. Later the hyphal tips are subcultures onto PDA plates. Though PDA is generally used media, many other media have also been used for endophytes isolation. To mention a few were YPS and Czapek medium, sporulation medium, MID, s7,FBM, REF,YPD. Among these maximum was found in MID. Even malt agar has been used for isolation of endophytes. ${ }^{[15]}$

In order to prevent bacterial contamination while preparing the inoculation media antibiotics like pencillin, tetracycline, streptomycin are added at required 
concentrations. ${ }^{[16,17]}$ In case of malt agar medium, chloramphenicol was used as antibiotic for better control of bacterial growth ${ }^{[15]}$.

The mycelia growth is observed for every $24 \mathrm{hrs}$ as few fungal strains tend to grow very fast and immediate transfer of hyphal tips to fresh media is required for proper pure culture isolation. ${ }^{[18]}$ The normal growth conditions were found to be around 25 degrees and it takes a period of 7-21 days for fungal growth to occur. This method of pure culture isolation is called as Hyphal tip method ${ }^{[19]}$.

This primary screening of endophytes is a very less expensive but laborious step. The number of isolates obtained would depend on the efficiency of surface sterilization performed for collected plant material, the sterility maintained, and source of inoculums like plant, root or leaf material that has been obtained ${ }^{[6,18,20]}$.

It seems that researchers have being trying to isolate Taxol producing endophytic fungi from different plants and the major difference was made by the type of host plant and fungal growth media used rather than the method of isolation.

\section{Screening of Taxol producing endophytic fungi}

Once endophytic fungi are isolated, researchers have tried to identify the Taxol producing endophytes using standard protocols ${ }^{[21,22,23]}$, One molecular biology approach used by researchers was to screen for the expression of Taxol synthese gene in endophytic fungi. ${ }^{[24]}$

The genes coding for 10-deacetylbaccatin III-10-O-acetyl transferase (DBAT) and C-13 phenylpropanoid side chain- CoA acyltransferase (BAPT) was used as molecular markers to screen Taxol producing endophytic fungi. ${ }^{[1]}$

For TLC detection, the fungus is grown for 7-10 days in liquid media and the filtrate is tested for Taxol production against standard on a TLC plate using vanillin spray.The taxol was detected with $1 \%$ vanillin in sulfuric acid (w/v) by gentle heating. It appeared as a bluish spot that faded to dark grey after $24 \mathrm{~h}$. Then, the area of the plate containing putative taxol was carefully removed by scraping off the silica at the appropriate Rf value and eluted with methanol followed by HPTLC and HPLC ${ }^{[1,25]}$

\section{Identification of Endophytic fungi}

Fungal identification is done based on its morphological and molecular characterization. Based on this, the fungi would be included into a specific taxonomic group. Morphological characterization of fungi can be done based on its growth pattern, hyphae structure, spore formation ${ }^{[26,]}$. 
Even staining techniques like lactophenol blue method is used for fungal identification $^{[16]}$. But these cannot assure the exact taxonomic identification of fungi. With the emergence of molecular biology and sequencing protocols, researchers have started using ITS sequencing for fungal identification where in the fungal genomic DNA is isolated using standard protocol and the ITS sequence is PCR amplified followed by sequencing and BLAST analysis. The newly identified fungi are deposited for NCBI

\section{Taxol purification}

Once the strain producing Taxol is identified the next step is to purify the molecule. Many researchers have used different protocols and techniques for Taxol purification. Generally fungal fermentation is done in a two step procees. Initially a sufficient amount of inoculum is added to liquid media. Once sufficient mycelia growth occurs it is transferred to fresh media for harvesting the secondary metabolite. As mentioned by few scientists, Mohammad Shoeb et al, 2012, they have grown the fungus on a semi solid medium for 21days, freeze dried the fungal material and extracted it using ethyl acetate ${ }^{[16]}$. This extract was evaporated to dryness and stored in $70 \%$ ethanol for further studies and analysis. Similarly different solvents have been used by researchers for extraction of fungus. For example Jatuporn Phaopongthai et al, 2013 has also used ethyl acetate for extraction of 20 litres of fungus culture. But he has done further column purification of the obtained ethyl acetate extract using solvents like nhexane, dicholoromethane and methanol on a sephadex 20 column $^{[7]}$.

In general the procedure for Taxol purification would be initial extraction of mycelia and filtrate using polar solvents like ethyl acetate, dichloromethane followed by freeze dry the extract and stored in solvents like methanol or ethanol ${ }^{[27]}$.

This obtained extract would be subjected to column chromatography using gradient isolation sytems and different solvents like acetonitrile, methanol, hexane based on the suitable polarity required the molecule is eluted. The major factors effecting the purification process would depend if the fungus produces the molecule extracellulary or intracellularly. If Taxol is produced intracellularly, then cell disruption has to be done initially followed by solvent extraction and purification. ${ }^{[12]}$

Various detection methods have been used by researchers for secondary metabolites confirmation. As mentioned by M.P. Patil the fungus culture filtrate was subjected to preparative TLC and plate development was carried out using solvents like Dichloromethane, methanol, chloroform, ethyl acetate and benzene in different ratios. After the separation the plates were observed under UV when derivatised by $5 \% \mathrm{H}_{2} \mathrm{SO}_{4} \cdot{ }^{[73]}$ The spectral data was obtained within the range of $200-700 \mathrm{~nm}$ and secondary metabolites were characterised. Similarly researchers have used analytical techniques like NMR, FTIR and X-RD for structural validation of the purified compounds. ${ }^{[, 6,28,29]}$ 


\section{Effect of Fungus purified biomolecules on different cell lines}

There has been many studies done by researchers to test the cytotoxicity of the fungal metabolite on different cell lines in comparision with standard drugs. ${ }^{[30]}$.They have tested the cytotoxicity of fungal strains IR 4, IR6 and IR7 on colon cancer cell lines CoCa2.These were isolated from Terminalia chebula plant. The ethyl acetate fractions have shown remarkable IC-50 values ranging from 55 to $71 \mathrm{mg} / \mathrm{ml}$. Further study of the crude extracts would help in identification of active metabolites which are responsible for this cytotoxic activity. Similarly Thangaraj A have isolated three fungal strains from roots of Terminalia arjuna plant and tested there anticancer property by MTT assay against breast cancer cell lines MCF 7 . The results obtained were significant and further study in this direction would help in identifying novel fungal strains with the capacity to produce anticancer drugs ${ }^{[31]}$. Ashraf S.A. El-Sayeda et al,2018 has identified and studied the anticancer activity of Taxol isolated from fungus Aspergillus terreus isolated from cork, leaves and twigs of Podocarpus plant. ${ }^{[32,33]}$ This study stands as a recent example for Taxol production in plants which do not belong to Taxus plant genera. The results obtained were note worthy. They tested the cytotoxicity against HEPG2 and MCF7 cell lines and the IC 50 was in the range of 4.5-6.5 nM. Similarly an endophyte named Curvularia has been identified from Terminalia laxiflora which had cytotoxic activity against NF kappa B and leukemia cell line KF62. This shows that different plants of Terminalia genera harbour the growth of many endophytic fungi which are capable of producing anticancer drugs which can be further purified and studied ${ }^{[15]}$.

Two fungal strains Aspergillus fumigates TXD105 and Alternaria tenuissima TER995, isolated from the bark of T. distichum and T. arjuna, respectively, were capable of producing paclitaxel and its anticancer activity has been tested against different cell lines namely HepG-2 (human liver cancer), HEp-2 (human larynx cancer), MCF-7 (human breast cancer), A-549 (human lung cancer), and CHO-K1 (hamster ovary cancer. ${ }^{[16]}$

Species named Pestalotiopsis has been isolated from Taxus cuspidata plant and it produced Palcitaxel around $478 \mathrm{microgram} / \mathrm{ml}$. Its cytotoxicity was tested against BT 220, HL 251, and HLK 210 cell lines. When compared with Taxomyces andreaneae isolated from same plant, Pestalotiopsis production rate was 9560 fold higher. ${ }^{[30]}$

A fungus named Lasiodiplodia theobromae has been isolated from Moringa citrifolia which was also producing Placitaxel and it has shown anticancer activity against MCF-7 breast cancer cell line and the Taxol yield was found to be around 245microgram/lit. This study could be further directed towards increasing the yield by process development and optimization techniques. ${ }^{[25]}$ 


\section{Genetic engineering for increasing Taxol production}

In most of the cases from $100 \mathrm{kgs}$ of plant material around 5-10 grams of secondary metabolites get extracted which is quite difficult and laborious process. Under such circumstances with the advancement of genetic engineering tools and techniques scientists have tried to develop bacterial and yeast platform systems for production of these high value compounds. One such study was done by Parayil Kumaran Ajikumar in 2010.They have developed a engineered $E$ coli strain to produce Taxadiene -the precursor of Taxol molecule. They have generated a yield of $1 \mathrm{gram} / \mathrm{litre}$. They have also engineered the next step of Taxol biosynthesis- P450-mediated 5a-oxidation of taxadiene to taxadien-5a-ol. This study paves a new path for MEP mediated pathway engineering for production of Taxol in prokaryotic systems. ${ }^{[32,33,34,]}$ Further researchers have tried to enhance the expression systems in Ecoli by combining various combinations of promoter sequences and it was found that change in the promoter sequences resulted in altered yields among different engineered strains. ${ }^{[35]}$

Later on with the identification of Taxol producing endophytic fungi, researchers have started working on these fungi and started engineering them for enhanced Taxol production. Once such study was done by Yamin Wei in 2012. They have inserted the rate limiting gene of Taxol synthesis- taxadiene synthase gene(ts) in an endophytic fungi Ozomium(EFY-21) using a yeast expression vector. This genetic transformation study resulted in increase in the yield of Taxol production by the fungi. Another fungi named Pestalotiopsis which produces Taxol was also screened for ts gene and the results were positive. ${ }^{[28]}$ Apart from that it was also found that the ts gene expression patterns were different when fungi were grown on solid and liquid media. ${ }^{[12]}$ This implies that media components and growth conditions play a major role in secondary metabolite expression by these endophytic fungi ${ }^{[36]}$.

\section{Conclusion- Future Prospects}

Though researcher's have tried to increase the yield of Taxol using hairy root cultures, endophyte based isolations, genetic engineering of bacterial systems, the world requirement is still not met. Taxol has been included in the World Health organisation's list of Essential medicines and it has been used since years for curing various types of cancers especially for breast cancer and ovarian cancer. India stands third in number of Breast cancer patients. If the breast cancer statistics is studied in India, 25 years back, out of every 100 breast cancer patients, $2 \%$ were in 20 to 30 years age group, $7 \%$ were in 30 to 40 and so on. $69 \%$ of the patients were above 50 years of age. Presently, $4 \%$ are in 20 to 30 yrs age group, $16 \%$ are in 30 to $40,28 \%$ are in 40 to 50 age group. So, almost $48 \%$ patients are below 50. An increasing numbers of patients are in the 25 to 40 years of age, and this definitely is a very disturbing trend. Though engineered prokaryotic systems have been developed, their yields are not very high and are very expensive and is a tedious process to develop a engineered prokaryotic strain. The current 
pharmaceutical market produces synthetic taxol which is highly expensive and alomost not affordable by many people across the globe. The global market cost of Palcitaxel for wholesalers for $30 \mathrm{mg}$ vial is 146.10 dollars which is very expensive. For an average 3 cycles treatment, the cost of the medicine would be around 1000 dollars for a cancer patient which is very much unaffordable by low income group.

Under such circumstances media optimization using statistical approaches like Placket Burmann Design, Response Surface Methodology and Design of Experiments for enhancing the yield of Taxol production by endophytic fungi would greatly benefit the society. Though researchers have been focussing on identifying new fungal strains and engineering them, much studies have not been done on this aspect. Further research in this direction would help in increasing the yield of high value compounds like Taxol and make this drug available to common public in a cost effective way.

\section{References}

1. Roopa, G., Madhusudhan, M.C., Sunil, K.C.R., Lisa, N., Calvin, R., Poornima, R., Zeinab, N., Kini, K.R., Prakash, H.S. and Geetha, N., 2015. Identification of Taxolproducing endophytic fungi isolated from Salacia oblonga through genomic mining approach. Journal of Genetic Engineering and Biotechnology, 13(2), pp.119-127.

2. Chowdhary, K., Kaushik, N., Coloma, A.G. and Raimundo, C.M., 2012. Endophytic fungi and their metabolites isolated from Indian medicinal plant. Phytochemistry reviews, 11(4), pp.467-485.

3. Demers, D.H., Knestrick, M.A., Fleeman, R., Tawfik, R., Azhari, A., Souza, A., Vesely, B., Netherton, M., Gupta, R., Colon, B.L. and Rice, C.A., 2018. Exploitation of mangrove endophytic fungi for infectious disease drug discovery. Marine drugs, 16(10), p.376.

4. Deng, B.W., Liu, K.H., Chen, W.Q., Ding, X.W. and Xie, X.C., 2009. Fusarium solani, Tax-3, a new endophytic taxol-producing fungus from Taxus chinensis. World Journal of Microbiology and Biotechnology, 25(1), pp.139-143.

5. Gangadevi, V. and Muthumary, J., 2009. Taxol production by Pestalotiopsis terminaliae, an endophytic fungus of Terminalia arjuna (arjun tree). Biotechnology and applied biochemistry, 52(1), pp.9-15.

6. Shoeb, M., Thoo-Lin, P.K. and Nahar, N., 2012. Anti-colon cancer activity of endophytic fungal strains from Terminalia chebula Rezt.||| Bangladesh Journal of Pharmacology|||, 7(1), pp.47-49.

7. Phaopongthai, J., Wiyakrutta, S., Meksuriyen, D., Sriubolmas, N. and Suwanborirux, K., 2013. Azole-synergistic anti-candidal activity of altenusin, a biphenyl metabolite of 
the endophytic fungus Alternaria alternata isolated from Terminalia chebula Retz. Journal of Microbiology, 51(6), pp.821-828.

8. Venkatachalam, R., Subban, K. and Paul, M.J., 2008. Taxol from Botryodiplodia theobromae (BT 115)-AN endophytic fungus of Taxus baccata. Journal of Biotechnology, (136), pp.S189-S190.

9. Toghueo, R.M.K., Kemgne, E.A.M., Sahal, D., Yadav, M., Kagho, D.U.K., Yang, B., Baker, B.J. and Boyom, F.F., 2021. Specialized antiplasmodial secondary metabolites from Aspergillus niger 58, an endophytic fungus from Terminalia catappa. Journal of Ethnopharmacology, 269, p.113672.

10. Chakravarthi, B.V.S.K., Das, P., Surendranath, K., Karande, A.A. and Jayabaskaran, C., 2008. Production of paclitaxel by Fusarium solani isolated from Taxus celebica. Journal of biosciences, 33(2), pp.259-267.

11. Somjaipeng, S., Medina, A. and Magan, N., 2016. Environmental stress and elicitors enhance taxol production by endophytic strains of Paraconiothyrium variabile and Epicoccum nigrum. Enzyme and microbial technology, 90, pp.69-75.

12. Maheshwari, V.L., Patil, M.P., Patil, R.H. and Patil, S.G., 2014. Endophytic Mycoflora of Indian medicinal plant, Terminalia arjuna and their biological activities. International Journal of Biotechnology for Wellness Industries, 3(2), pp.53-61.

13. Chang-Tian, L., Yu, L., Wang, Q.J. and Sung, C.K., 2008. Taxol production by Fusarium arthrosporioides isolated from yew, Taxus cuspidata. Journal of Medical Biochemistry, 27(4), pp.454-458.

14. Liu, K., Ding, X., Deng, B. and Chen, W., 2009. Isolation and characterization of endophytic taxol-producing fungi from Taxus chinensis. Journal of Industrial Microbiology and Biotechnology, 36(9), p.1171.

15. Tawfike, A.F., Abbott, G., Young, L. and Edrada-Ebel, R., 2018. Metabolomic-guided isolation of bioactive natural products from Curvularia sp., an endophytic fungus of Terminalia laxiflora. Planta medica, 84(03), pp.182-190.

16. Ismaiel, A.A., Ahmed, A.S., Hassan, I.A., El-Sayed, E.S.R. and El-Din, A.Z.A.K., 2017. Production of paclitaxel with anticancer activity by two local fungal endophytes, Aspergillus fumigatus and Alternaria tenuissima. Applied microbiology and biotechnology, 101(14), pp.5831-5846.

17. Qiao, W., Ling, F., Yu, L., Huang, Y. and Wang, T., 2017. Enhancing taxol production in a novel endophytic fungus, Aspergillus aculeatinus Tax-6, isolated from Taxus chinensis var. mairei. Fungal biology, 121(12), pp.1037-1044. 
18. Pavithra, N., Sathish, L. and Ananda, K., 2012. Antimicrobial and enzyme activity of endophytic fungi isolated from Tulsi. Journal of Pharmaceutical and Biomedical Sciences (JPBMS), 16(16), p.2014.

19. Wang, J., Li, G., Lu, H., Zheng, Z., Huang, Y. and Su, W., 2000. Taxol from Tubercularia sp. strain TF5, an endophytic fungus of Taxus mairei. FEMS Microbiology Letters, 193(2), pp.249-253.

20. Chandra, S., 2012. Endophytic fungi: novel sources of anticancer lead molecules. Applied microbiology and biotechnology, 95(1), pp.47-59.

21. Zhao, K., Ping, W., Li, Q., Hao, S., Zhao, L., Gao, T. and Zhou, D., 2009. Aspergillus niger var. taxi, a new species variant of taxol-producing fungus isolated from Taxus cuspidata in China. Journal of applied microbiology, 107(4), pp.1202-1207.

22. Zhang, P., Zhou, P.P. and Yu, L.J., 2009. An endophytic taxol-producing fungus from Taxus media, Cladosporium cladosporioides MD2. Current microbiology, 59(3), pp.227232.

23. Zaiyou, J., Li, M. and Xiqiao, H., 2017. An endophytic fungus efficiently producing paclitaxel isolated from Taxus wallichiana var. mairei. Medicine, 96(27).

24. Kumaran, R.S., Muthumary, J. and Hur, B.K., 2009. Isolation and identification of an anticancer drug, taxol from Phyllosticta tabernaemontanae, a leaf spot fungus of an angiosperm, Wrightia tinctoria. The journal of microbiology, 47(1), p.40.

25. Pandi, M., Kumaran, R.S., Choi, Y.K., Kim, H.J. and Muthumary, J., 2011. Isolation and detection of taxol, an anticancer drug produced from Lasiodiplodia theobromae, an endophytic fungus of the medicinal plant Morinda citrifolia. African Journal of Biotechnology, 10(8), pp.1428-1435.

26 Soliman, S.S., Tsao, R. and Raizada, M.N., 2011. Chemical inhibitors suggest endophytic fungal paclitaxel is derived from both mevalonate and non-mevalonate-like pathways. Journal of natural products, 74(12), pp.2497-2504.

27. Kumaran, R.S., Muthumary, J. and Hur, B.K., 2008. Taxol from Phyllosticta citricarpa, a leaf spot fungus of the angiosperm Citrus medica. Journal of bioscience and bioengineering, 106(1), pp.103-106.

28. Wei, Y., Zhou, X., Liu, L., Lu, J., Wang, Z., Yu, G., Hu, L., Lin, J., Sun, X. and Tang, $K ., 2010$. An efficient transformation system of taxol-producing endophytic fungus EFY21 (Ozonium sp.). African Journal of Biotechnology, 9(12). 
29. Netala, V.R., Bethu, M.S., Pushpalatha, B., Baki, V.B., Aishwarya, S., Rao, J.V. and Tartte, V., 2016. Biogenesis of silver nanoparticles using endophytic fungus Pestalotiopsis microspora and evaluation of their antioxidant and anticancer activities. International journal of nanomedicine, 11, p.5683.

30. Majoumouo, M.S., Tincho, M.B., Kouipou Toghueo, R.M., Morris, T., Hiss, D.C., Boyom, F.F. and Mandal, C., 2020. Cytotoxicity potential of endophytic fungi extracts from Terminalia catappa against human cervical cancer cells. Journal of toxicology, 2020.

31. Thangaraj, A. and Fathima, M., 2017. Dual Role of Endophytic Fungi from the Roots of Terminalia arjuna (Roxb.) Wight \& Arn. Journal of Pharmaceutical and Biomedical Sciences, 7(6).

32. Ajikumar, P.K., Xiao, W.H., Tyo, K.E., Wang, Y., Simeon, F., Leonard, E., Mucha, O., Phon, T.H., Pfeifer, B. and Stephanopoulos, G., 2010. Isoprenoid pathway optimization for Taxol precursor overproduction in Escherichia coli. Science, 330(6000), pp.70-74.

33. Xiong, Z.Q., Yang, Y.Y., Zhao, N. and Wang, Y., 2013. Diversity of endophytic fungi and screening of fungal paclitaxel producer from Anglojap yew, Taxus x media. BMC microbiology, 13(1), pp.1-10.

34. Xu, F., Tao, W., Cheng, L. and Guo, L., 2006. Strain improvement and optimization of the media of taxol-producing fungus Fusarium maire. Biochemical Engineering Journal, 31(1), pp.67-73.

35. Boghigian, B.A., Salas, D., Ajikumar, P.K., Stephanopoulos, G. and Pfeifer, B.A., 2012. Analysis of heterologous taxadiene production in $K$-and B-derived Escherichia coli. Applied microbiology and biotechnology, 93(4), pp.1651-1661.

36. Zhou, X., Zhu, H., Liu, L., Lin, J. and Tang, K., 2010. A review: recent advances and future prospects of taxol-producing endophytic fungi. Applied microbiology and biotechnology, 86(6), pp.1707-1717.

37. Uzma, F., Mohan, C.D., Hashem, A., Konappa, N.M., Rangappa, S., Kamath, P.V., Singh, B.P., Mudili, V., Gupta, V.K., Siddaiah, C.N. and Chowdappa, S., 2018. Endophytic fungi-alternative sources of cytotoxic compounds: a review. Frontiers in pharmacology, 9, p.309. 